\title{
Questōes sobre a atualidade de Brecht
}

\author{
Sérgio de Carvalho
}

N

essa homenagem a Roberto Schwarz, quero mencionar um episódio de sua atuação crítica que teve relação direta com os caminhos artísticos de meu grupo de trabalho teatral, a Companhia do Latão. O primeiro evento público em que a Companhia do Latão adotou esse nome, assumindo-se, portanto, como um coletivo artístico, ocorreu em de julho de 1997, na abertura de portas do Teatro de Arena de São Paulo, espaço então ocupado por nós com o projeto Pesquisa em Teatro Dialético. Roberto Schwarz participou da noite inaugural como palestrante convidado: após a leitura da peça Santa Joana dos Matadouros, encenada por nós e por ele traduzida, veio debater conosco a atualidade da obra de Bertolt Brecht.

Esse acontecimento artístico - e crítico foi para nós tão importante que nos obrigou de imediato a pensar sobre o sentido do que estávamos fazendo, e de certo modo, até hoje o trabalho do grupo dialoga, na concordância ou na divergência, com as posições apresentadas por Roberto Schwarz naquele primeiro encontro.

Até então, vivíamos numa espécie de fase intuitiva do interesse pela junção entre teatro e política, mas já sabíamos que qualquer aprendizado nessa área teria que passar pelo estudo da obra de Brecht. Assim, os eixos daquele nosso primeiro projeto de pesquisa em "dialética teatral" visava aspectos complementares da produção brechtiana, a teoria e a dramaturgia. A primeira dessas frentes formativas se organizou em torno da experimentação prática com $A$ Compra do Latão, conjunto de escritos teorizantes inconclusos de Brecht, que viemos a conhecer através do livro O Trabalho de Brecht, de José Antonio Pasta Jr.. E a segunda frente, que visava à poética ficcional de Brecht, cuidou da análise - através de uma leitura cênica - da peça Santa Joana dos Matadouros, com a qual tínhamos tomado contato também através da teoria - o ensaio de Roberto Schwarz publicado em Que horas são?

A bem da verdade, a pesquisa da Companhia do Latão nasceu de duas apostas feitas no escuro, referendadas pela confiança em intelectuais que tanto admirávamos (e que estão hoje aqui presentes). Nosso interesse, desde o início, não estava, portanto, só em Brecht, mas na junção artística entre ficção e teoria (esboçada já

Sérgio de Carvalho é dramaturgo, encenador e Professor do Departamento de Artes Cências da ECAUSP. Este texto resulta da transcrição de sua fala quando da homenagem ao crítico Roberto Schwarz, ocorrida na Faculdade de Filosofia Ciências e Letras da USP, no Seminário Crítica Materialista no Brasil: a obra de Roberto Schwarz, auditório Fernand Braudel, em 24 de agosto de 2004. 
no espetáculo Ensaio para Danton) e numa possível leitura crítica do teatro épico no Brasil de hoje, o que o trabalho de Pasta Jr. e Schwarz nos sugeria ser uma necessidade da própria postura dialética do autor.

Minha admiração anterior pelo trabalho de Roberto Schwarz vinha de razões muito particulares, pouco ligadas a Brecht ou Machado de Assis. Estudei, durante o Mestrado, a obra do crítico de origem alemã Anatol Rosenfeld, o que me levou à leitura do ensaio de Roberto sobre o "intelectual estrangeiro" Rosenfeld, um dos mais belos textos da nossa crítica. Qualquer autor de um ensaio como aquele tinha, para mim, uma credencial notável: conheceu pessoalmente Rosenfeld e sabia imprimir essa relação viva na escrita. Naquela época eu ganhava a vida como colaborador do caderno cultural de um grande jornal da cidade, para o qual tinha sugerido que se organizasse uma página literária de homenagem a Rosenfeld. Telefonei, então, a Roberto Schwarz pedindo um depoimento, que me foi enviado por escrito, transmitido num papel de fax, que guardo até hoje, mesmo com as letras se apagando (como tudo que é belo, o texto desapareceu). Eu gostaria de ler esse depoimento aqui, não é maior do que um parágrafo, e diz respeito ao tema da minha fala - a relação entre a obra de Roberto Schwarz e a de Brecht:

\footnotetext{
A liberdade intelectual do Anatol era surpreendente

o segredo estava nas coisas deprimentes que ele não fazia.

Não passava a perna nos outros,

não vivia atrás de vantagens,

Não cortejava os influentes,

não negociava elogios,

tinha horror à autopromoção,

não se deslumbrava com a celebridade alheia,

nem com a própria,

em contrapartida tinha uma clareza nada convencional

quanto ao que vale a pena.

O pessoal que confunde liberdade e baixaria achava o Anatol quadrado.
}

Esse textinho sempre me pareceu fora do comum: de maneira clássica ele tece, pela via negativa, a imagem do comportamento do Anatol e culmina numa sentença positiva fulminante: "Em contrapartida tinha uma clareza nada convencional quanto ao que vale a pena". Ainda acho que isso pode mudar a vida de alguém: clareza quanto ao que vale a pena. $\mathrm{O}$ pensamento de Anatol Rosenfeld, flagrado no seu gesto intelectual, na sua atitude ética e crítica fundamental, era para mim uma poética.

Imaginem, portanto, a expectativa gerada pela vinda de Roberto Schwarz ao Teatro de Arena. Abriríamos o teatrinho com uma homenagem a Brecht feita por um grande crítico de esquerda, e ainda por cima um "rosenfeldiano".

A frase inaugural da conferência veio logo depois dos aplausos animados aos atores, quando ainda se desobstruía o palco dos adereços para dar lugar à cadeira do convidado. Caiu como raio num céu sem nuvens, apesar da fala suave do crítico de olhos apertados, que nos dizia ao se ajeitar: "Eu vou ser muito breve, e começar pelas razões pelas quais Brecht perdeu a atualidade". Brecht, que gostava de contradições, talvez não reprovasse o procedimento, nos informou com um sorriso. E o que se ouviu, na seqüência, foi uma impressionante exposição sobre a desatualização de Brecht, sobre os vários aspectos do teatro épico que teriam perdido o pé na contemporaneidade, passíveis de serem considerados ultrapassados pela nova ordem do mundo, aspectos que solicitariam, portanto, reinvenção histórica. Imaginem o silêncio tenso da audiência.

Tempos depois, quando reescreveu a conferência do Arena para a publicação no volume Seqüências Brasileiras, Roberto incluiu uma frase que não foi dita na ocasião mas que traduzia perfeitamente a nossa sensação: "Com a licença de vocês, vou fazer o papel de advogado do diabo." A brilhante palestra daquele advogado do diabo foi nosso batismo de água gelada. 


\section{Dinamização capitalista}

O ponto de partida da argumentação de Roberto Schwarz foi o conceito de distanciamento, apresentado como núcleo fundamental da teoria brechtiana. Ao mostrar o vínculo entre a proposição estética central de Brecht e a teoria marxista da desnaturalização, ao mostrar que o conceito-chave da poética cênica de Brecht se liga ao método materialista da desmontagem ideológica, de dissolução da aparência de naturalidade (e imutabilidade) das representações a partir do choque com sua perspectiva histórica material, Roberto nos sugeria também que a confiança épica na transformação precisaria ser repensada nos dias de hoje por um grupo que adota Brecht como modelo para um teatro radical. Isso por duas razões ligadas a um mesmo processo: por um lado, o Socialismo histórico se modificou, deixando - segundo ele - de ser a referência direta para uma crítica anticapitalista; e por outro lado, o modo de produção capitalista teria se tornado a grande força dinâmica da sociedade atual, o que lançaria uma suspeita sobre o elogio da mutabilidade.

Não sei se resumo bem a palestra, mas quero sublinhar o recorte escolhido para o problema: na medida em que o distanciamento de Brecht apontava - com base na historicização dos processos capitalistas - para a possibilidade de um outro mundo - e foi isso que entusiasmou a geração que nos anos 60 leu a obra de Brecht no Brasil - Roberto nos perguntava: para onde nos remete agora a crítica anticapitalista se ela já não indica com tanta clareza um quadro socialista como superação histórica da etapa anterior? Como incorporar o fato de que o capital se tornou um fator dinâmico na atualidade também no plano simbólico, aparecendo hoje pouco associado a ideologias de ares conservadores?

Um exemplo complicador disso, para Roberto Schwarz, é que a própria elite capitalista passou a incorporar o marxismo no discurso, em chave invertida, ao postular o pragmatismo econômico como argumento justificador de seus atos. Se a técnica básica de desvendamento anti-ideológico de Brecht nascia do atrito entre o idealismo burguês e o motivo econômico, teríamos um problema com essa técnica num tempo em que a idéia da geração de riqueza a qualquer preço se tornou soberana: governos neoliberais como o de Fernando Henrique e Lula evocam razões econômicas para justificar suas decisões e indecisões políticas. Ninguém tem problemas em admitir que a primazia é material, que a economia governa a vida pública. Diante disso, para que serviria um teatro interessado em desvelar a causalidade econômica? E num nível mais prosaico, para que serviria um teatro que tem no seu centro uma técnica famosa - o distanciamento - já desvirtuada a ponto de ter sido, segundo opinião de Roberto, incorporada pela publicidade? Um exemplo célebre seria o anúncio com o garoto da Bombril, que expõe os recursos narrativos da propaganda para se pôr ao lado do comprador na observação adesionista ao produto.

Ao ouvir esses argumentos meus sentimentos eram contraditórios. De imediato eu já notava algumas falhas na exposição: nossos primeiros exercícios e leituras de Brecht nos indicavam que não se pode considerar o Distanciamento como uma técnica - puramente formal -, sendo antes um efeito que se realiza na percepção social gerada pela representação. Tempos depois confirmei essa idéia ao descobrir que Brecht já previa em seus escritos um uso "puramente técnico" da prática teatral distanciadora, a que ele chamava de uso demonizado ou demoníaco, que pode aparecer tanto nas antigas tradiçôes orientais em que o teatro chama a atenção para seu jogo formal, como na vanguarda mais formalista ou ainda, acrescentaria eu, na comunicação de massa. No teatro épicodialético, por outro lado, o efeito de distanciamento se dá na relação historicizante estabelecida pelo trabalho dialético que ocorre no trânsito crítico (e vivo) entre palco e platéia, trabalho desapassivador, que gera uma disposição à atitude reflexiva conjunta ao desfrute estético da forma representacional. O efeito não se completa sem que a imagem cênica ofereça consigo 
uma possibilidade de indagação sobre sua perecibilidade, sua transformabilidade histórica, ou sobre a causalidade social do acontecimento mostrado ou sugerido pela cena.

Além disso, o vínculo entre a potência poética de Brecht e a esperança no Socialismo histórico me parecia fácil demais, mais próprio à analogia do que ao pensamento causal, na medida em que para Brecht o distanciamento era uma ferramenta de ativação dialética: como Marx, Brecht recusava qualquer noção estática de Comunismo, entendendo sua prática e conceito como um movimento. No entanto é importante reconhecer que sua postura estética engajada teria tido menor impacto social se não fosse potencialmente associável à proximidade (ilusória ou não) do Socialismo. O exemplo do Teatro de Arena e do seu trabalho de renovação estética não pode ser bem avaliado sem a dimensão de sentido extra-estético gerada pelo desejo de transformação social.

Mas esses pontos em que Roberto Schwarz parecia estar equivocado também não eram suficientes para invalidar o conjunto do seu argumento, que trazia uma perturbadora lucidez. Em síntese, na contramão de nossa expectativa de celebração, ele dizia o seguinte: existe um grande risco de ideologizar um teatro anti-ideológico como o de Brecht se não levarmos em conta a conjuntura atual e os rumos do capitalismo hoje.

\section{Espécies de negatividade}

Um dos jeitos de avaliar as sensações ambíguas geradas por aquela noite batismal da Companhia do Latão foi reconhecer na fala de Roberto Schwarz os ecos de um certo Theodor Adorno, cujo pensamento sempre me impressionou pela agudeza das observações e pela pouca disposição em facilitar a prática coletiva. Quando foi publicada tempos depois, a conferência de Roberto Schwarz teve várias de suas partes reescritas. Entre elas estava o final - um desfecho em que ele parecia assumir essa filiação adornia- na mais direta, ao dizer que, diante da desatualização da obra de Brecht, permaneceria um núcleo de potência estética justamente na negatividade. Num teatro como o de Brecht, que de fato trabalha com a chamada "matéria negativa”, com o lixo da sociedade, com comportamentos grotescamente criticáveis, com exposição pelo avesso, com a capacidade de ver o melhor no pior, só o aprofundamento da sondagem negativa pode gerar uma perspectiva contemporânea. Essa visão poética adorniana (que não se desassemelha da leitura de Heiner Muller sobre Brecht) aparece na seguinte frase, que eu li como um conselho: "O que há é, dentro do negativo, a possibilidade de encontrar uma brecha que nos permita ver o quão negativo é esse negativo no qual chafurdamos".

Evidentemente, nunca veio a ser esse o projeto estético da Companhia do Latão, mas também é preciso dizer que nunca desdenhamos do conselho a ponto de buscar o contrário disso. Ainda hoje me parece que a crítica estética de Adorno, válida em tantos campos, quando discute o engajamento de Brecht recai em estereótipos grosseiros, mostrando-se mesmo incapaz de discutir o uso radical que Brecht faz $\mathrm{da}$ ingenuidade como categoria épica. Pior do que isso me parece o pathos trágico que envolve o estilo epigramático das sentenças de Adorno: existe algo de psicologizante (e depressivo) na constatação de que a única arte digna desse nome - no atual estado de barbárie - é aquela que procura dar forma ao absolutamente inumano. E para Adorno o inumano não é representável, ele é no máximo reconhecível. É como se - diante do avanço desmesurado do fetichismo da mercadoria - a representação estivesse impossibilitada. A hipótese poética decorrente dessa filosofia estética é assim contrária a qualquer "conteúdo social manifesto" porque, no estágio em que o fetichismo se completa não existe mais representação.

Como alguém interessado nas particularidades vivas do mundo real, como alguém que encontra no trabalho coletivo de arte um indício simbólico da realização de uma vida menos 
alienada e pré-determinada, eu não consigo achar que vale a pena uma perspectiva poética em que o rigor analítico não se conjuga ao gosto pela produção viva, em que a lucidez sobre $o$ que é não mobiliza a invenção do que podia ser. E não considero verdadeira uma visão de mundo que parece estabilizar o processo da dominação capitalista ao decretar como absoluto o esmagamento do sujeito, desconsiderando o sentido político da contradição entre as forças produtivas e as relações de produção. Já vi, no campo da arte, isso redundar em neonaturalização do capital (convertido na famosa imagem da "máquina-cega") ou em fetichismo estético, que aposta no simbolismo da liberdade criativa em abstrato, como se a Arte fosse um lugar do puro sensível que não se contamina pelas formalizaçôes da vida.

É preciso dizer, entretanto, - e esse é um ponto importante -, que o sentimento de paralisia gerado pelas palavras de Roberto Schwarz naquela noite era contrabalançado por dois aspectos ligados à forma e ao método de sua exposição: a sua relação com o tema da palestra e, mais ainda, com a expectativa do público, era evidentemente de oposição: negativa segundo a melhor prática dialética - tipicamente brechtiana - de não encerrar no palco uma verdade completa. Além disso, seu raciocínio de contramão se envolvia por uma atitude pessoal muito entusiasmada em debater problemas complexos nos quais não tínhamos ainda pensado.

Havia, portanto, uma dimensão extradiscursiva operando também no seu método e atitude. E uma pessoa de teatro não pode desconsiderar isso: nem que as formas dizem às vezes mais do que os assuntos (os enunciados formais são tantas vezes mais eloqüentes do que os enunciados temáticos) e nem que a arte, por mais formalista que seja, também atua numa dimensão extra-estética, porque, no mínimo, o espectador jamais deixa de projetar ou imaginar algo sobre o sujeito e o trabalho da obra.

Ao perceber que aquela palestra nos dizia coisas importantes também por sua forma crítica, acabei por eleger, na ocasião, um tema fun- damental de trabalho entre os tantos propostos pelo palestrante - que veio a orientar muito da postura estética da Companhia do Latão nos anos seguintes. A certa altura, talvez no debate que seguiu à palestra, Roberto Schwarz nos perguntou: $\mathrm{O}$ que agrupa as pessoas hoje? $\mathrm{O}$ que o distanciamento ainda pode agrupar? Que tipo de relação coletiva ele pode construir?

Alguns meses depois daquele dia, quando Santa Joana dos Matadouros se tornou um espetáculo e fez temporada, ainda pensávamos naquelas palavras, procurando verificar na prática o que desmentia ou o que dava razão a Roberto, que hipóteses teóricas se mostravam frágeis, e quais se confirmavam sem apelo, e mais do que isso, qual a razão coletiva de estarmos ali.

A eficácia crítica do chamado Efeito de Distanciamento veio a se mostrar, ao menos para nós, muito mais mobilizadora do que supunha a avaliação inaugural do Roberto. Não tenho a menor dúvida que a dialética brechtiana, em sua heterodoxia imaginativa, é ainda uma ferramenta teatral extremamente potente e útil - desde que capaz de contribuir para uma perspectiva historicizadora. Está longe de ser de conhecimento geral que as representações humanas não são naturais. Os véus ideológicos contemporâneos são muito fortes e elásticos, e mesmo que não sejam mais baseados nas crenças tradicionais (ou no idealismo clássico) continuam hábeis em eternizar as dinâmicas totalizantes do capitalismo em imagens de aparência eterna. Não acho demais dizer que existe em curso um novo processo de naturalização dos valores, não mais baseado nas relações produtivas tradicionais, mas na sua falência, não mais baseado em idéias decretadas, mas na ignorância histórica, e mais do que tudo, decorrente do totalitarismo das dinâmicas capitalistas no mundo atual. É um outro estágio do processo de naturalização, em que conhecimento de que o dinheiro não é a alma das coisas do mundo pouco pode diante da sua violência material quando diz que é. Diante disso, uma prática artística de representação desnaturalizadora ainda tem vali- 
dade crítica não por expor um assunto mais ou menos óbvio, não por seu aspecto puramente temático ou epistemológico, mas por sugerir formas simbólicas de agregação e mobilização, tanto no plano sensível como nas relações de trabalho. A própria carreira fora-do-comum de nossa montagem de Santa Joana parecia confirmar um duplo prazer produtivo do espectador: repensar as imagens em perspectiva histórica parecia tão prazeroso quanto verificar que também outras pessoas se interessavam pela junção produtiva entre forma experimental e politização do debate.

Por outro lado, aquilo que Roberto considerava o mais ultrapassado - a temática social explícita e a mola econômica evidenciada, tornadas suspeitas pela condenação de Adorno também demonstrava uma força de agregação enorme, em parte por razões extra-estéticas. A ausência desse tipo de assunto dos palcos contemporâneos, contraposta à livre imaginação formal de um jovem grupo de teatro, instaurava uma perturbação com certas convençõos teatrais vigentes. A própria evidência da temática social - ao ser historicizada numa montagem que convidava o espectador a pensar sobre as diferenças entre o texto e a atualidade - agia como elemento ativador. Platéias de estudantes e de movimentos sociais, que passaram a freqüentar o teatro, vinham atrás da junção entre o tema proscrito - a luta de classes - e a radicalidade estética.

$\mathrm{O}$ assunto também - e não só a pesquisa poética negativa - tem mérito no interesse despertado por Brecht naquele ano 1998. Estou certo de que se não é mais tão nova a revelação de que o dinheiro é quem organiza a moral social, por outro lado é ainda revelador perceber que isso pode ser objeto de uma obra de arte, sobretudo numa formalização tão radical como aquela, que fazia, por exemplo, uso irônico de um metaforismo ainda vigente no noticiário sobre as bolsas de valores, que teima em aludir, naturalisticamente, ao "humor" ou aos "cataclismas" do mundo dos negócios.
Entretanto, era preciso concordar com Roberto Schwarz que o pólo mais vibrante da técnica artística de Brecht se ligava mesmo a uma atitude negativa dos versos, das personagens, das camadas da ação cênica. $O$ métodoBrecht é também um método negativo (tal como o exemplificava o próprio palestrante Roberto quando punha em contradição seu gesto intelectual com o sentido das palavras), com a diferença de que o teatro épico-dialético oferece materiais ao espectador para que o Não se converta num trabalho em aberto fora do palco. Basta citar aqui um exemplo mais evidente: as grandes personagens da nossa encenação eram mesmo Pedro Paulo Bocarra e seus comparsas cínicos, representantes de um capitalismo lírico, sentimental e violento. O impacto estético da peça provinha de sua negatividade critivável, disposta ao movimento. Isso inclusive se tornou problemático quando verificamos que parte da platéia tendia a distensionar o juízo ao simpatizar com essa desfaçatez cínica, sem ver nela a contrapartida trágica. Tivemos que interferir na ordem do texto aumentar a conexão entre a individualidade negativa e a violência do capital, mas sem jamais absolutizar o sentimento tragicizante. E nesse sentido realizávamos muito da sugestão de Roberto: adulteramos a peça - historicizando Brecht - para manter sua força de contradição e capacidade de gerar movimento.

No ensaio "Altos e baixos da atualidade de Brecht" encontro hoje uma explicação mais nítida sobre a qualidade própria do negativismo brechtiano (que reaviva a lembrança daquela contraditória noite inaugural). Ali, na reescritura, o crítico Roberto Schwarz, de uma maneira muito livre, pensando sobre o Brasil ou sobre qualquer tema, parece praticar, na verdade, uma mútua correção entre Adorno e Brecht, o que acredito ser também um procedimento constitutivo de seu modo crítico. Quando se aprofunda na análise da peça Santa Joana, Roberto observa (coisa que não fez diante de nós) que na forma poética das falas dos capitalistas existe uma aceleração progressiva da negativida- 
de estética. O texto da peça, de início, demonstra feições idealistas, pois afinal são personagens que ainda têm como referência mental a tradição clássica da arte do Sujeito moral - e por isso Brecht compõe seu discurso a partir de paródias de Goethe e Schiller. Mas em pouco tempo esse idealismo é superado pela voz da esperteza, que é superada pela cegueira. É como se o movimento do cinismo voraz que sustenta o idealismo conduzisse a uma entropia que ensejasse a sua superação. Ocorre um acúmulo de discursos autofágicos. Roberto observa em Brecht a capacidade de reproduzir na forma das personagens a dinâmica do capital, em sua autodevoração e auto-recriação contínuas. Essa dinamização brutal do capitalismo - que deixa a vida para trás no mesmo impulso que parece organicamente vivo - é sem dúvida um dos aspectos mais impressionantes que se pode ler na forma dos escritos teatrais de Brecht e talvez isso seja um modo próprio de expressar a desumanização. Passados 7 anos, esse é um aspecto que nos tem muito interessado ao escrever a peça Visões Siamesas, que não por acaso dialoga com o tema adorniano do reconhecimento do inumano, sem qualquer tragicidade paralisante, sem perda do desejo de lucidez.

Esse olhar radicalmente negativo para o Nada: que no limite conduz ao Nada (perspectiva que também aparece na obra de Machado de Assis), talvez seja uma estratégia de arte modelar quando não se recusa à vivência da tensão entre sujeito e objeto, caso não naufrague na miragem pós-modernista de que toda linguagem que se autonega perscruta o inumano.

Roberto, no seu ensaio, escreve o seguinte, em termos muito palpáveis: "O capitalismo transformou em mentira barata a literatura que insiste em desconhecer o esmagamento dos pobres diabos que somos".
A literatura, portanto, que tem a capacidade de reconhecer esse esmagamento não abre mão de indagar seu sentido diante da realidade, mesmo que exclusivamente a partir de suas determinações formais. No último parágrafo, ele nos oferece uma sugestão poética ainda mais direta sobre a possibilidade de compreensão do método Brecht de ativação, tal como lido por um crítico que admira a Dialética Negativa: "Brecht preferiu ficar na penúltima etapa da fetichização. Um passo aquém da delegação completa da energia social ao mercado. O resultado é uma iluminação de viés. Que faz ver a face não mercantil dos negócios (aquele velho idealismo da burguesia, que não era bom na origem) e não deixa que o fetichismo se complete, ou que o capital pareça ser apenas capital.”

É nessa escolha do ponto aquém, por meio dessa iluminação de viés, um ponto antes do fetichismo completo - em que a forma mantém um pé no aquém e no além da sociedade burguesa -, é nessa capacidade de objetualizar o processo de objetualização da vida, que eu acredito residir muito da força artística de Brecht. Se Brecht avançou tanto no que se refere a uma politização produtiva da forma é porque considerava que sua unidade não está no palco, mas na relação com a platéia. Nenhum de seus gestos existe sem a relação com o que está fora dele, o que nos sugere um jeito desautomatizador (e muito interessado nos pontos de transformação) de se pensar a relação possível entre pesquisa da vida contemporânea, a reflexão estética e radicalização política.

No fundo, o método Brecht, tal como Roberto o concebe em sua atitude crítica, se parece muito com aquela pequena e luminosa descrição de Rosenfeld: uma perspectiva negativa associada à procura de uma clareza nada convencional quanto ao que vale a pena. 